\title{
A progressive pericardial effusion caused by psittacosis
}

\author{
SIMON R PAGE, * JAMES T STEWART, † JOANNA J BERNSTEIN* \\ From the ${ }^{\star}$ Department of Medicine II, and the †Cardiology Department, St George's Hospital, London
}

SUMMARY A patient developed signs of a progressive pericardial effusion over a period of eight days. Diagnostic and therapeutic pericardiocentesis was performed. Viral titres to psittacosis rose from $<1: 8$ to $>1: 256$ indicating recent infection.

Chlamydial infections produce a wide variety of clinical problems but rarely affect the heart. ${ }^{1} \mathrm{We}$ describe a case of acute pericarditis caused by psittacosis in which a large pericardial effusion required pericardiocentesis.

\section{Case report}

In a 55 year old woman a central constricting chest pain developed and became worse over two days. It was associated with dry cough and breathlessness. There was no past history of heart disease. She was taking thyroxine $(200 \mu \mathrm{g}$ daily) for longstanding primary hypothyroidism and prednisolone $(5 \mathrm{mg}$ daily) for late onset asthma. She smoked 20 cigarettes per day.

On examination she looked flushed but was otherwise well. Her temperature was $38^{\circ} \mathrm{C}$, her pulse was 86 per minute and regular, and her blood pressure was $160 / 90 \mathrm{~mm} \mathrm{Hg}$. The jugular venous pressure was not raised and the heart sounds were normal. No friction rub was heard. Chest examination revealed an expiratory wheeze and the peak expiratory flow rate was $270 \mathrm{l} / \mathrm{min}$.

The white cell count was $13.7 \times 10^{9} / 1(79 \%$ neutrophils) and the erythrocyte sedimentation rate was $68 \mathrm{~mm} / \mathrm{h}$ (Westergren). Cardiac enzymes, the electrocardiograph, and chest radiograph were normal. Eighteen hours after admission left anterior pleuropericardial pain and atrial fibrillation developed. Examination of the arterial blood gases showed pH 7.438 (normal range 7.35-7.45), partial pressure of oxygen $\left(\mathrm{Po}_{2}\right) 11.1 \mathrm{kPa}$ (normal range 12$15 \mathrm{kPa})$, partial pressure of carbon dioxide $\left(\mathrm{PCO}_{2}\right)$ $4.63 \mathrm{kPa}$ (normal range $4.5-6.0 \mathrm{kPa}$ ) on air. An electrocardiogram confirmed atrial fibrillation but

Requests for reprints to Dr Simon R Page, Department of Medicine II, St George's Hospital, London SW 17 ORE. was otherwise unchanged, and the chest radiograph remained normal. Pulmonary embolism was suspected and treatment with heparin (15000 units twice daily) was started. Twelve hours later a further electrocardiograph showed sinus rhythm with atrial supraventricular extrasystoles and concave upward ST elevation in both the anterior and inferior leads. Anticoagulation was stopped because of suspected pericarditis. A repeat chest radiograph showed no change of heart size.

Three days after admission she developed further pain, rapid atrial fibrillation and the blood pressure fell to $90,60 \mathrm{~mm} \mathrm{Hg}$. A pericardial friction rub was heard at the left sternal edge. A chest radiograph now showed an increase in the ize of the cardiac silhouette and a left basal pleural effusion. Cross sectional echocardiography confirmed a pericardial effusion and showed a cystic lesion in the region of the posterior tricuspid valve leaflet (fig 1). Antinuclear antibodies and anticardiac antibodies were negative; serum viral titres for Coxsackie B1-B6, influenza $\mathrm{A}+\mathrm{B}$, mumps, and psittacosis/lymphogranuloma venereum were all $<1: 8$. A Mantoux reaction was positive at a $1: 1000$ dilution.

She improved after treatment with digoxin, indomethacin ( $50 \mathrm{mg}$ three times daily), and erythromycin (500 $\mathrm{mg}$ four times a day). Sinus rhythm was restored, blood pressure rose, and she had less pain. An intermittent fever (up to $38.5^{\circ} \mathrm{C}$ ) persisted.

During the next week the size of the pericardial effusion increased considerably on the chest radiograph (fig 2) and cross sectional echocardiograph. The jugular venous pressure rose to $9 \mathrm{~cm}$ and the blood pressure averaged $100 / 70 \mathrm{~mm} \mathrm{Hg}$. Diagnostic and therapeutic pericardiocentesis was performed because of the signs of progressive subacute tamponade. We withdrew $500 \mathrm{ml}$ of blood stained pericardial fluid. Microbiological studies of the fluid including examination for acid and alcohol 


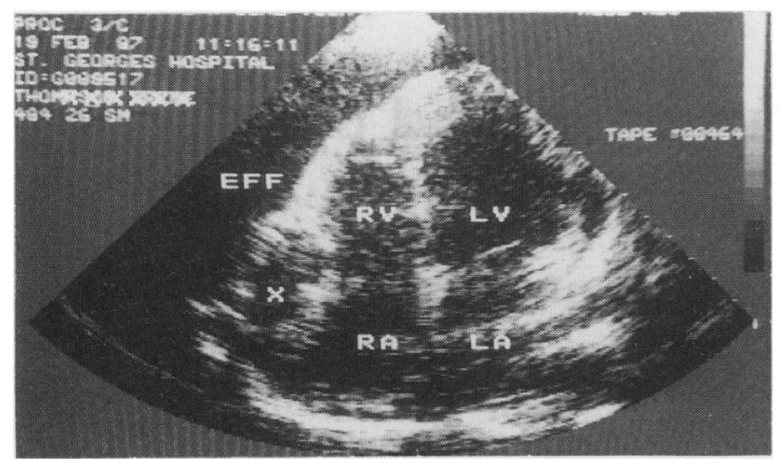

Fig 1 Cross sectional echocardiograph performed three days after admission. EFF, effusion; $X$, cystic lesion; $R A$, right atrium; $R V$, right ventricle; $L A$, left atrium; $L V$, left ventricle.

fast bacilli as well as cytological examination were negative. After the procedure the cystic lesion was no longer visible on cross sectional echocardiographs.

Fifteen days after admission the titre of antibody to psittacosis/lymphogranuloma venereum measured by complement fixation and immunofluorescence techniques rose to $>1: 256$ from the initial value of $<1: 8$. Oxytetracycline ( $500 \mathrm{mg}$ four times daily) was started. The temperature became normal over five days and the left basal pleural effusion disappeared over two weeks.

A one month course of treatment was planned, but after three weeks the pericardial and pleural effusions and the chest pain recurred. The effusions resolved within one week with bed rest and indomethacin (500 mg four times daily). Oxytetracycline was continued for two months in total. No further relapses occurred during four months of follow up and the

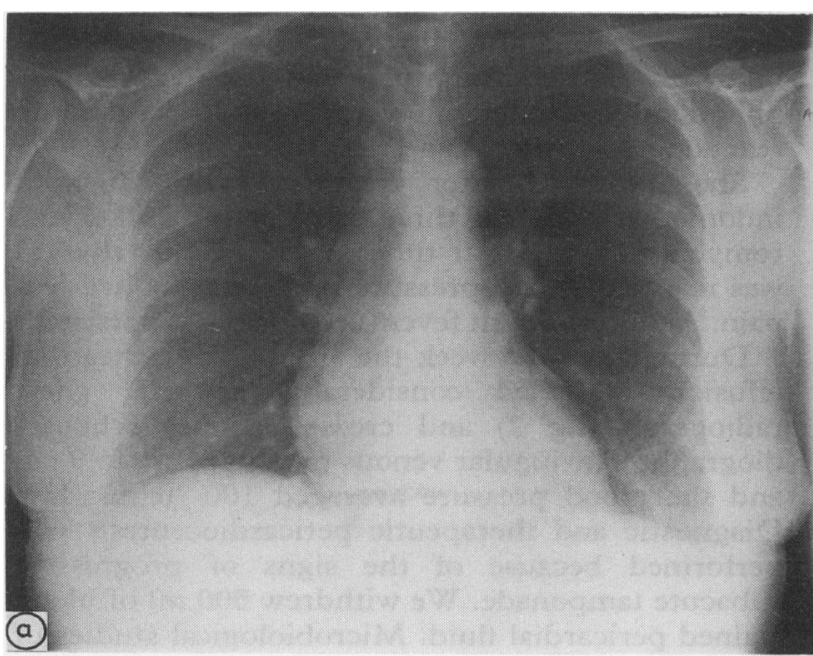

Fig 2 Chest radiographs taken on admission ( $a$ ) and nine days after admission (b).

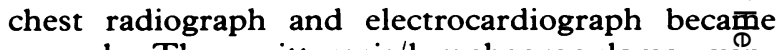
normal. The psittacosis/lymphogranuloma v@ $\stackrel{\mathbb{1}}{\bar{z}-}$ ereum titre fell to $1: 8$.

On enquiry the patient reported brief exposure tie parrot two weeks before admission. The ow refused to let us investigate the bird.

\section{Discussion}

Acute Chlamydia psittaci infection is usually transmitted by inhalation of the dried excreta of psittacine birds and in most cases produces a respiratory illness. The diagnosis is by serology, and an antibody titrof 1:16 to the group specific antigen of the psittacosis/ lymphogranuloma venereum group is regarded positive. ${ }^{2}$ Cardiac involvement is rare and of êt complicates psittacosis related respiratory diseasis. ${ }^{3}$ Both endocarditis ${ }^{45}$ and myocarditis ${ }^{67}$ have bejen reported and the small number of necropsy repofts show endocardial involvement as the major pathological feature. ${ }^{1}$ We found only three reported cases of documented pericardial effusion caused by psittacosis. ${ }^{38}$ To our knowledge this is the first repor $8 \mathrm{~d}$ case of the development of a large pericardial effusion requiring pericardiocentesis after psittacosis. THe rise and fall of the antibody titre to the Chlamydiacsae group specific antigen was considerable and there were no features of ocular or genital disease or \%at scratch fever to suggest Chlamydia trachomatis inf $\&$ tion, which is a cause of false positive results. ${ }^{9}$ Tfle lungs were only slightly affected; she had a dry coutgh at presentation and a small left sided pleural effusion developed. The response to standard antibiotics was slow but this was a feature of the case reported $-7 y$ Kundu and $\mathrm{Scott}^{8}$ and may reflect the difficulty@in

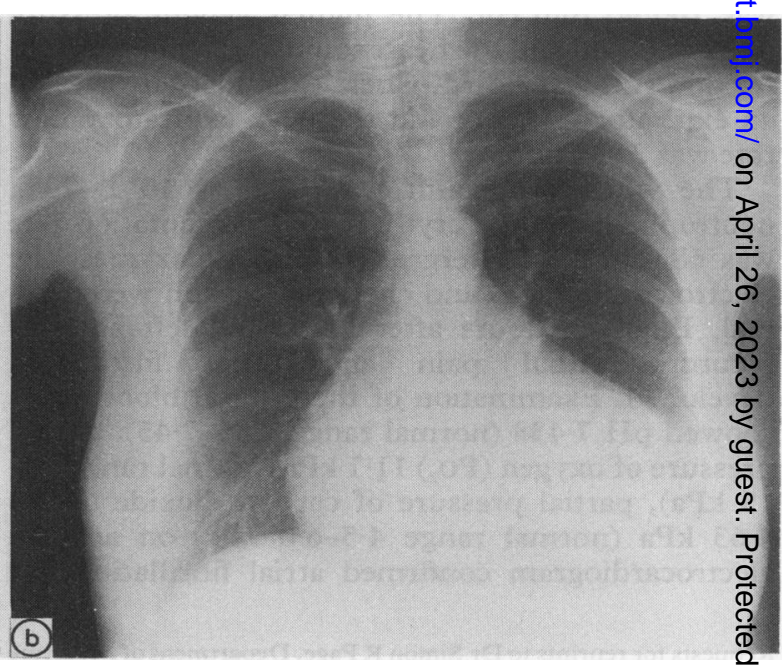


eradicating the organism from the pericardial effusion.

Sutton et al, in a review of 599 unselected cases of acute pericarditis, found nine cases with serological evidence of psittacosis, with pericardial effusions in two. ${ }^{3}$ In four cases heart disease was the only clinical manifestation. In six patients the diagnosis was by serology, with an antibody titre $>1: 32$. No titres $>1: 16$ were recorded in a control population of 1000 . Five patients recovered completely but their treatment regimens were not reported.

The nature of the cystic lesion seen on initial echocardiography remains uncertain. It most probably represents encysted pericardial fluid and rupture during pericardiocentesis may account for its disappearance.

It is often difficult to obtain an accurate history of bird exposure in psittacosis. ${ }^{10}$ In the present case the history of exposure was obtained only after serological diagnosis. We therefore recommend the measurement of antibody titres of psittacosis/lymphogranuloma venereum titres in all cases of acute pericarditis regardless of pulmonary involvement. If the diagnosis is confirmed treatment with oxytetracycline should be continued for at least two months.

We thank Professor J S Jenkins for permission to report this case and to Mr G Leach for the echocardiography.

\section{References}

1 Ward C. "Rheumatic" heart disease, psittacosis and the importance of epidemiology. Am Heart J 1978; 95:266-7.

2 Treharne JD. Chlamydial infections: laboratory aspects. In: Harris JWR, ed. Recent advances in sexually transmitted diseases. vol 2. Edinburgh: Churchill Livingstone, 1981:141-50.

3 Sutton GC, Morrisey RA, Tobin JR Jr, Anderson TO. Pericardial and myocardial disease associated with serological evidence of infection by agents of the psittacosis/lymphogranuloma venereum group (Chlamydiaceae). Circulation 1967;4:830-8.

4 Levinson DA, Guthrie W, Ward C, Green DM, Robertson PGC. Infective endocarditis as part of psittacosis. Lancet 1971;ii:844-7.

5 Jariwalla AG, Davies BH, White J. Infective endocarditis complicating psittacosis: response to rifampicin. Br Med J 1980;280:155.

6 Reid JM, Kennedy JF, McArthur J. Unusual cause of atrial fibrillation. $\mathrm{Br}$ Med $J$ 1982;284:237-8.

7 Coll R, Horner I. Cardiac involvement in psittacosis. $\mathrm{Br}$ Med J 1967;4:35-6.

8 Kundu CR, Scott ME. Pericardial effusion complicating psittacosis infection. Br Heart $J$ 1979;42:603-5.

9 Schachter J, Dawson CR. Human chlamydial infections. Littleton, Massachusetts: PSG Publishing, 1978.

10 Anderson JP. Ornithosis in Somerset. Experience in the south Somerset clinical area; 1964-1971. Postgrad Med J 1973;49:533-4. 